\title{
Industrial chimney monitoring - contemporary methods
}

\author{
Olga Kaszowska ${ }^{1}$, Piotr Gruchlik ${ }^{1}$ and Wiestaw Mika ${ }^{1}$ \\ ${ }^{1}$ Główny Instytut Górnictwa (Central Mining Institute), Katowice, Poland
}

\begin{abstract}
The paper presents knowledge acquired during the monitoring of a flue-gas stack, performed as part of technical and scientific surveillance of mining activity and its impact on industrial objects. The chimney is located in an area impacted by mining activity since the 1970s, from a coal mine which is no longer in existence. In the period of 2013-16, this area was subject to mining carried out by a mining entrepreneur who currently holds a license to excavate hard coal. Periodic measurements of the deflection of the 113-meter chimney are performed using conventional geodetic methods. The GIG used 3 methods to observe the stack: landbased 3D laser scanning, continuous deflection monitoring with a laser sensor, and drone-based visual inspections. The drone offered the possibility to closely inspect the upper sections of the flue-gas stack, which are difficult to see from the ground level.
\end{abstract}

Keywords: building object, safety, mining area, observations, measurements

\section{Introduction}

Over recent decades, intensive development has been observed in the area of measuring instruments and appliances and the related advancement of measuring methods. They are used to observe surface deformation and the deformation of buildings and structures caused by underground mining. The methods include: terrestrial (land-based) and airborne laser scanning (Light Detection and Ranging - LiDAR), GPS measurements, and interferometric synthetic aperture radar measurement (InSAR). Sensors, inclinometers, tensometers and lasers are used to observe deformations of land surface and buildings within an area impacted by mining. It should be emphasized, however, that the new technologies are encumbered with certain limitations, as are traditional ones. By using them, much more data can undoubtedly be obtained, and this technology can be used for continuous measurements or monitoring. However, not all of these technologies yield sufficiently accurate data.

Despite the impressive development of measuring technologies, classical methods are still in use. Experience shows that geodetic methods continue to be indispensable whenever highly accurate coordinates need to be obtained for land surface points, buildings, structures, and changes thereof. 
The decision on which technologies are to be used in specific conditions should not be driven by the method being "new" or "old", but should be based on the potential to accomplish the goal of the measurement, i.e. to obtain data of the required accuracy. The optimisation of the observation also includes its costs.

This paper presents an interesting problem, a solution to which was sought in the course of surveillance performed by the Central Mining Institute. Due to the specific features of the chimney, the optimal decision was to use several measuring technologies and perform remote observations of its technical condition.

Surveillance of the 113-meter chimney includes checking its deflection and technical condition. Periodic measurements of the chimney deflection were accomplished using traditional geodetic methods. The Central Mining Institute used 2 methods for checking the chimney geometry (primarily its deflection): land-based 3D laser scanning, and deflection monitoring using a laser sensor. Additionally drone-based visual inspections were made. Using a drone enables the ongoing assessment of the technical condition of the chimney, with no need to make use of climbers.

This paper describes the knowledge gained from comprehensive observations of the high flue-gas stack using classical geodetic methods and new technologies.

\section{Chimney description}

The chimney was erected in the first half of the 1940s and it serves to discharge hot $\left(122-170^{\circ} \mathrm{C}\right)$ flue gas from coke-fired and hard-coal-fired boilers. Its current height is 113 meters. Originally it was 115 meters high but in 1997 it was shortened by 2.05 meters. It is a ceramic chimney with a circular cross-section (Fig. 1, 2). The chimney diameter is $7.64 \mathrm{~m}$ at ground level, and $3.5 \mathrm{~m}$ at flue-gas outlet level. The shaft is made of stack brick, and the inner lining, of up to 40 meters, of clay bricks. The chimney's foundation is a reinforcedconcrete circular plate with a diameter of $17.0 \mathrm{~m}$, positioned $5 \mathrm{~m}$ below ground level. It is adjacent to a boiler house (Fig. 10) but they are separated by an expansion joint.

Before the mining activity started, the chimney had displayed considerable vertical deflection. Due to the potential increase of the deflection as a result of the planned mining operations, the chimney was placed under surveillance.

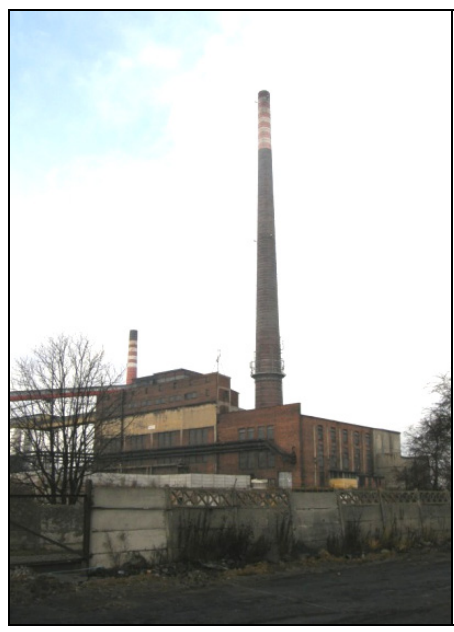

Fig. 1. View of the chimney

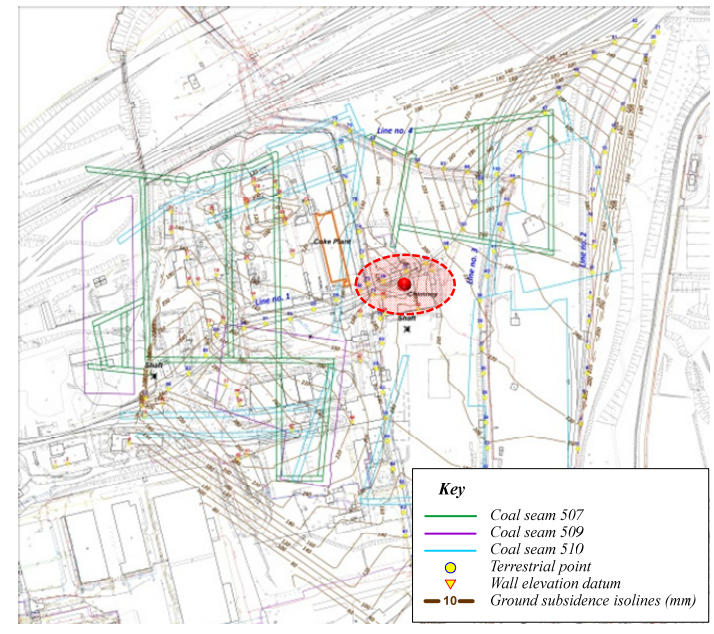

Fig. 2. The chimney location in respect of the mining plots and iso-lines of surface subsidence measured in the period of $2012-2016$ 


\section{Geodetic measurements}

The boiler house chimney was subjected to the impacts of hard coal mining activity conducted during the period of 2013-2016 in three coal seams. Due to the specific conditions of building and structure protection, an experimental system of drift mining was used. Fig. 2 shows the location of the chimney and the mining operations.

\subsection{Measurement of surface deformations caused by mining activity}

Geodetic measurements of surface deformation started in September 2012. They included the levelling of dispersed points and levelling and length measurements along the lines shown in Fig. 2. The last levelling was made at the end of 2016.

The stabilised points of line 1 and line 4 are closest to the stack. Subsidence of approximately $0.16 \mathrm{~m}$ occurred within the chimney area. Interpolation of the measurement results led to the delineation of surface deflection iso-lines (Fig. 2) and calculation of land inclination increase. At the chimney site, the increase is $0.5 \mathrm{~mm} / \mathrm{m} \mathrm{SE}$. At the height of $113 \mathrm{~m}$, i.e. the flue-gas outlet, the deflection changes by $5.6 \mathrm{~cm}$. However, one must remember that the deflection of buildings and structures does not always correspond to land inclination changes.

Additionally, calculations were made using the Budryk-Knothe method, applied by Polish coal mines to predict the impact of mining activity. The parameters in this model were determined by matching theoretical profiles of subsidence troughs and those measured along the observation lines.

The theoretically calculated subsidence within the area of the chimney is $150 \mathrm{~mm}$ and the inclination is $1.4 \mathrm{~mm} / \mathrm{m}$. If the chimney deflection corresponded exactly to the surface inclination, the theoretical increase of the deflection at flue gas outlet level would be $15.8 \mathrm{~cm}$.

\subsection{Measurement of chimney deflection}

The initial geodetic measurement was performed before the commencement of mining, in April 2011. All observations showed deflation of the structure at $55-64 \mathrm{~cm}$ in a northeastern direction (Table 1). The azimuth was $46-67^{\circ}$ (computed clockwise from the north). The resultant deflection according to the last measurement of September 2017 is $56 \mathrm{~cm}$, azimuth $63^{\circ}$. The mean error of deflection determined using this method is $\pm 3.0 \mathrm{~cm}$.

The measurements were made by determining the coordinates of the chimney centre at two levels: the ground level and the flue gas outlet level. Determination of the location of the upper section poses no problems, but the lower section is accessible only at half of its perimeter, as it is adjacent to the building. During the first measurement, coordinates of the centre at ground level were determined from the inside of the chimney during a break in its operation. However, breaks in chimney operation are too infrequent to make simultaneous measurements of its base and the upper section viable.

Chimney deflection was computed using the coordinates of the bottom part's centre determined in 2011 and the current coordinates of the upper section's centre. This means that the deflections determined using geodetic measurements are subject to a non-random error. Undoubtedly, the mining activity causes not only displacement of the chimney at the flue gas outlet level, which results from inclination and dislocation of the area surface, but also dislocation of its base. For the purpose of calculation, the coordinates determined in the first measuring cycle were taken into account, so the dislocation of the base centre was disregarded. Since determination of this figure was not technically feasible, other methods were used to measure the chimney's deflection. 
Table 1. List of chimney top deflection values measured by geodetic methods

\begin{tabular}{|c|c|c|c|}
\hline Item & $\begin{array}{l}\text { Measurement } \\
\text { Date }\end{array}$ & $\begin{array}{c}\text { Deflection } \\
\text { of chimney top } \\
\text { [cm] }\end{array}$ & $\begin{array}{c}\begin{array}{c}\text { Direction of } \\
\text { deflection }\end{array} \\
\text { [ ] }\end{array}$ \\
\hline 1 & Apr 2011 & 57 & $49^{\circ} 51^{\prime}$ \\
\hline 2 & Oct 2011 & 56 & $52^{\circ} 24^{\prime}$ \\
\hline 3 & Dec 2011 & 55 & $55^{\circ} 49^{\prime}$ \\
\hline 4 & Apr 2012 & 57 & $55^{\circ} 21^{\prime}$ \\
\hline 5 & Oct 2012 & 59 & $55^{\circ} 34^{\prime}$ \\
\hline 6 & Apr 2013 & 55 & $52^{\circ} 16^{\prime}$ \\
\hline 7 & Oct 2013 & 60 & $56^{\circ} 56^{\prime}$ \\
\hline 8 & Apr 2014 & 55 & $49^{\circ} 32^{\prime}$ \\
\hline 9 & Oct 2014 & 56 & $51^{\circ} 43^{\prime}$ \\
\hline 10 & Mar 2015 & 56 & $50^{\circ} 47^{\prime}$ \\
\hline 11 & Jul 2015 & 57 & $50^{\circ} 47^{\prime}$ \\
\hline 12 & Sept 2015 & 58 & $46^{\circ} 01^{\prime}$ \\
\hline 13 & Apr 2016 & 58 & $51^{\circ} 31^{\prime}$ \\
\hline 14 & Sept 2016 & 64 & $55^{\circ} 27^{\prime}$ \\
\hline 15 & Oct 2016 & 63 & $57^{\circ} 00^{\prime}$ \\
\hline 16 & Apr 2017 & 57 & $67^{\circ} 03^{\prime}$ \\
\hline 17 & Sept 2017 & 56 & $63^{\circ} 21^{\prime}$ \\
\hline
\end{tabular}

\section{Continuous measurement of deflection}

In the period from March to December 2016, the chimney underwent continuous measurements of deflections, using a laser sensor constructed at GIG [1]. The sensor and the recording device were installed on the chimney base wall approximately $2 \mathrm{~m}$ above the ground level (Fig. 3a).

The sensor is based on a module of a vibration and deflection sensor with the following measuring parameters:

- range of measurement: $5 \mathrm{~mm} / \mathrm{m}$ (possible adjustment to 2 to $50 \mathrm{~mm} / \mathrm{m}$ ),

- resolution: $0.02 \mathrm{~mm} / \mathrm{m}$,

- vibration frequency $<10 \mathrm{~Hz}$.

With the sensor, the building deflection can be measured accurately, continuously and automatically. The measurement is made by registering the vertical deflection of the laser beam after it passes a liquid-filled wedge (Fig. 3b). The outcome of the measurement, in the form of a graphic printout on a recorder tape, offers a full picture of deflections, both in terms of their value, direction, and duration.

The results of the continuous monitoring of the chimney base deflection are presented in a diagram of changes in the values and direction of the resultant deflection vector (Fig. 4). The monitoring demonstrated that noticeable deflection of the chimney base started on 28 June and lasted until August 2016, i.e. over the period of the strongest impact of the mining activity on the surface of the chimney site. On 8 July, a change was observed in the deflection in the south-eastern direction, and from 14 July - a significant increase in the south-western direction. On 4 and 5 August, the resultant deflection in this direction was $2.3 \mathrm{~mm} / \mathrm{m}$ and subsequently it gradually diminished and the resultant deflection changed its direction to north-eastern. This tendency was observed until mid-November, when the deflection decreased to $0.72 \mathrm{~mm} / \mathrm{m}$. In December 2016, the deflection became stable. 
a)

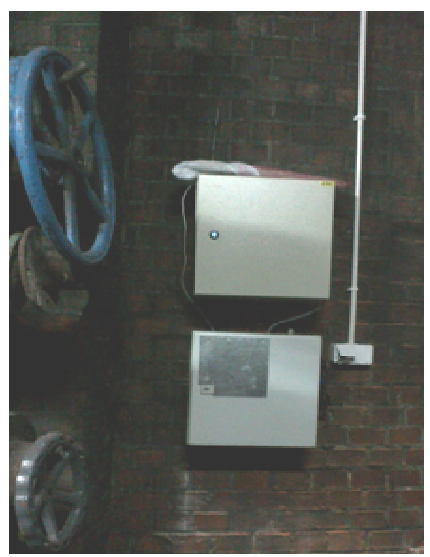

b)

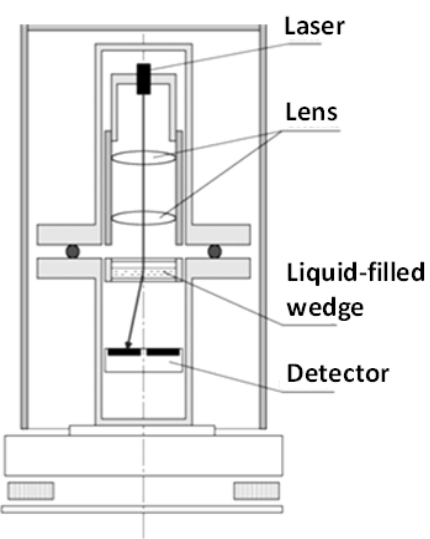

Fig. 3. Laser sensor for continuous measurement of deflections a) a view of the sensor and the recorder, b) the sensor diagram

Compared to the initial position on the date of the commencement of the measurement, the chimney base showed a displacement in the south-western direction, oscillating around a mean value of $1.0 \mathrm{~mm} / \mathrm{m}$.

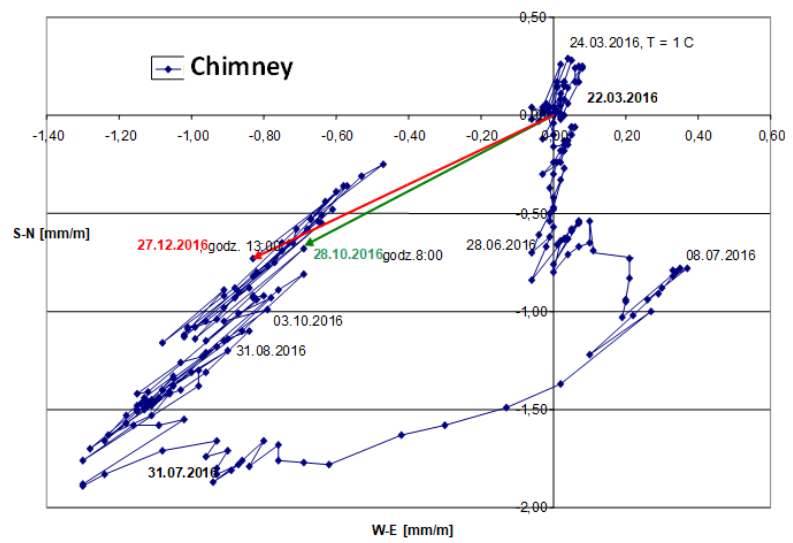

Fig. 4. Chimney base deflection vectors from the date of laser sensor installation

\section{Land-based 3D laser scanning}

As part of the surveillance, in the period from July 2015 until December 2017, nine measurements of the chimney were performed using ground-based 3D laser scanning. The long-distance 3D laser scanners Trimble TX8 and Riegl VZ-4000 were used.

The 3D Trimble TX8 is an ultra-high speed, phase-shift, long-distance scanner (Fig. 5). It can capture up to one million points per second while maintaining high accuracy over the entire scan range, within the scan range of up to $340 \mathrm{~m}$ and broad field of view $\left(317^{\circ} \times 360^{\circ}\right)$.

Riegl VZ-4000 is an impulse terrestrial long-range scanner (Fig. 6). Its operating range is $5-4000 \mathrm{~m}$ in favourable air conditions (medium air transparency) and low reflectiveness. It works with maximum efficiency within the range of $1 \mathrm{~km}$. Riegl VZ-4000 is among the fastest of its type: it works with a frequency of $50-300 \mathrm{kHz}$ $(37-222$ thousand points/s). 


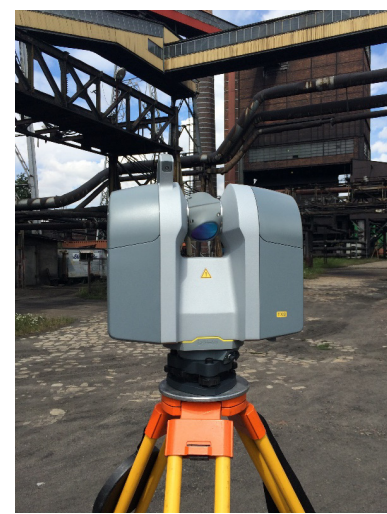

Fig. 5. 3D Trimble TX8

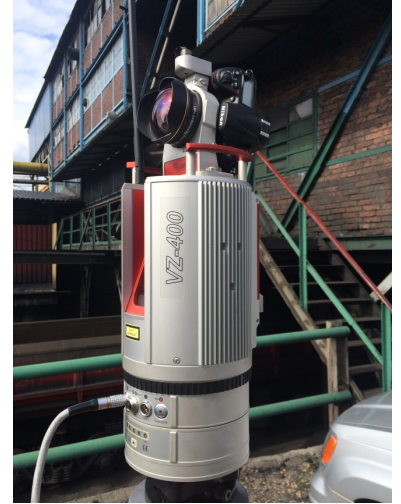

Fig. 6. 3D Riegl VZ-4000

The chimney measurements were made from four scanner workstations. Their positioning is shown in Fig. 7 [2]. The data obtained from measurements, in the form of point clouds, was registered. The absolute orientation of the points was determined. The transformation is based on clearly identifiable overlapping points in point clouds. The points can be natural or artificial. Natural targets are the selected chimney points. Artificial targets are spheres inserted in the measured space.

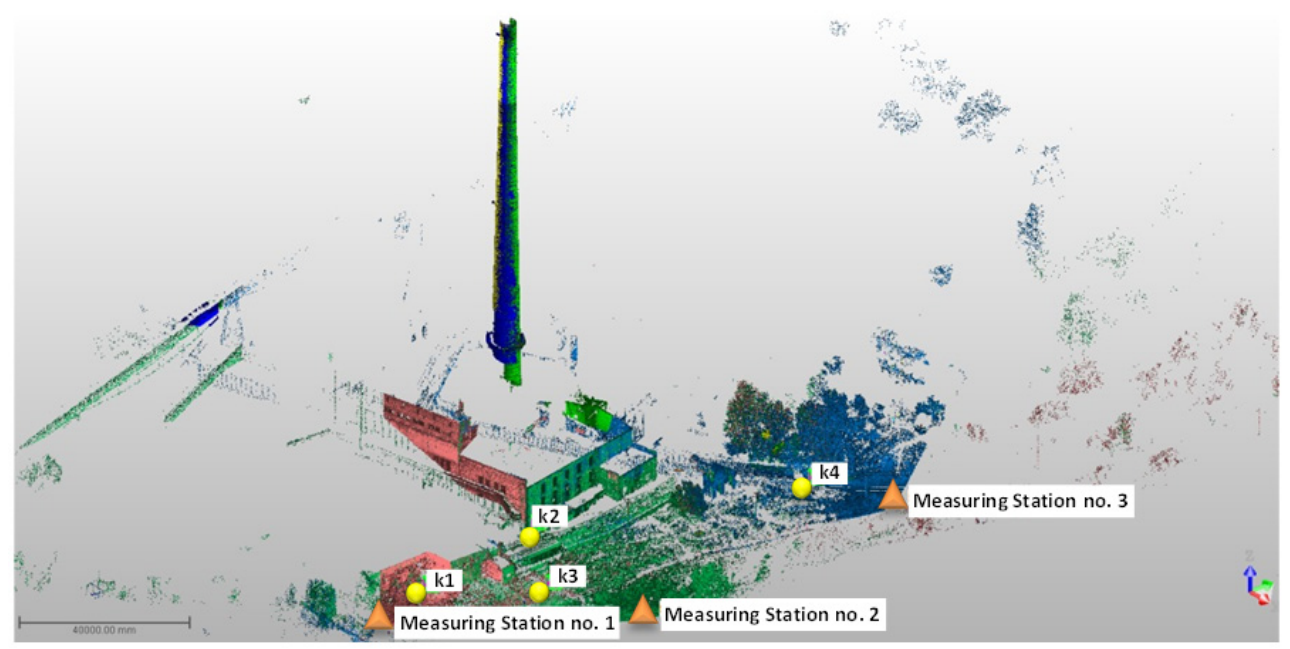

Fig. 7. Layout of measuring stations and spheres (k1-k4) for chimney measurement

The processing of data generated by the 3D laser scanner measurements was done using Trimble Real Works 10.3 software.

The 3D chimney model made from point clouds (Fig. 8) was scrutinised. The chimney cross-sections were prepared, spaced at a distance of $1 \mathrm{~m}$. The location of the circular section centre on successive horizontal lines was analysed, and the direction and value of chimney deflection was determined at each level (Fig. 9).

The measurements are presented in Table 2. Each measurement is accompanied with a brief note on the ambient conditions in which it was taken. 


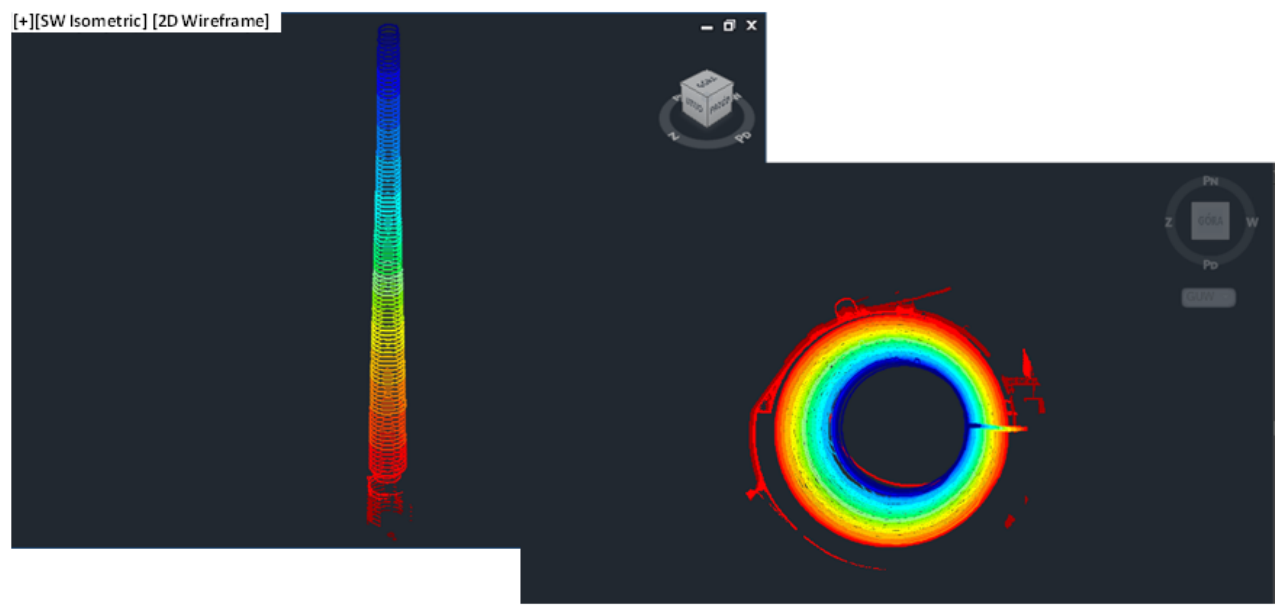

Fig. 8. Chimney model and its cross sections on successive horizontal lines

In December 2017, the chimney deflection was $546 \mathrm{~mm}$ in the north-eastern direction (azimuth $62^{\circ}$ ). With respect to the measurement of June 2017, the deflection decreased by $29 \mathrm{~mm}$, and the azimuth changed by $5^{\circ}$ to the southern direction.

Table 2. List of chimney top deflections measured by laser scanning

\begin{tabular}{|c|c|c|c|c|c|}
\hline Item & $\begin{array}{c}\text { Measurement } \\
\text { Date }\end{array}$ & $\begin{array}{c}\text { Deflection } \\
{[\mathrm{mm}]}\end{array}$ & $\begin{array}{c}\text { Deflection } \\
\text { Direction } \\
{\left[{ }^{\circ}\right]}\end{array}$ & Scanner type & $\begin{array}{c}\text { Ambient conditions } \\
\text { air temperature } \\
\text { wind direction and flow } \\
\text { velocity }\end{array}$ \\
\hline 1 & 29.07 .2015 & 560 & 55 & Trimble TX8 & $21^{\circ} \mathrm{C} ; \mathrm{SW} 19 \mathrm{~km} / \mathrm{h}$ \\
\hline 2 & 04.11 .2015 & 556 & 51 & Trimble TX8 & $11^{\circ} \mathrm{C} ; \mathrm{WSW} 13 \mathrm{~km} / \mathrm{h}$ \\
\hline 3 & 18.03 .2016 & 546 & 54 & Trimble TX8 & $10^{\circ} \mathrm{C} ; \mathrm{W} 21 \mathrm{~km} / \mathrm{h}$ \\
\hline 4 & 21.06 .2016 & 541 & 64 & Riegl VZ-4000 & $21^{\circ} \mathrm{C} ; \mathrm{SW} 14 \mathrm{~km} / \mathrm{h}$ \\
\hline 5 & 26.09 .2016 & 560 & 58 & Riegl VZ-4000 & $18^{\circ} \mathrm{C}, \mathrm{EEW} 10 \mathrm{~km} / \mathrm{h}$ \\
\hline 6 & 18.10 .2016 & 593 & 58 & Riegl VZ-4000 & $11^{\circ} \mathrm{C}, \mathrm{SSW}, 18 \mathrm{~km} / \mathrm{h}$ \\
\hline 7 & 22.12 .2016 & 583 & 60 & Riegl VZ-4000 & $-1^{\circ} \mathrm{C}, \mathrm{SSW}, 20 \mathrm{~km} / \mathrm{h}$ \\
\hline 8 & 09.06 .2017 & 575 & 57 & Riegl VZ-4000 & $23^{\circ} \mathrm{C} ; \mathrm{SE} 9 \mathrm{~km} / \mathrm{h}$ \\
\hline 9 & 12.12 .2017 & 546 & 62 & Riegl VZ-4000 & $10^{\circ} \mathrm{C} ; \mathrm{SSW} 21 \mathrm{~km} / \mathrm{h}$ \\
\hline
\end{tabular}

\section{Checks of the technical condition}

The chimney was repaired in 1997. Before mining activity started, it showed no major damage, except for some local thermal cracking. During the mining activity carried out within the chimney site, systematic ground-based observation is made using binoculars and

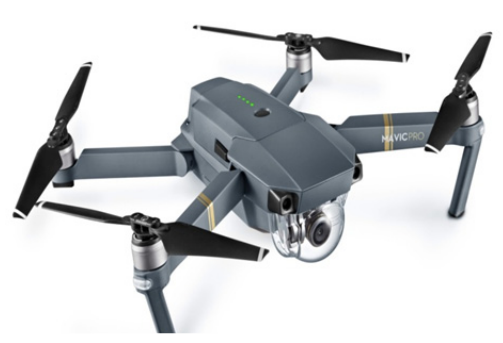

Fig. 9. The drone cameras equipped with telephoto lens. In October each year, during a several-day technological break in boiler house operation, the condition of the chimney facade and interior is inspected by climbers.

In June 2017, a chimney technical check was made using an unmanned aerial vehicle commonly called a drone [3]. The checks were made using a DJI MAVIC Pro drone (Fig. 9).

With the drone, the technical conditions of the external brick wall of the chimney could be assessed, 
along its entire height, with accuracy comparable to direct visual inspection. The check showed ovalisation of the chimney shaft cross-section at the outlet (Fig. 10) which could not be detected using traditional inspection methods.

In October 2017, during a ground-based inspection of the chimney condition, a crack along a joint was observed at the height of approximately $35 \mathrm{~m}$, from the south-western side. The inspecting personnel indicated that the crack was not clearly visible on previous checks. The analysis of photographs taken earlier indicates that the damage was already there in May 2015. Another inspection of the chimney's technical conditions, made with the drone in November 2017, demonstrated that the technical condition of the chimney shaft wall did not significantly change at this point (Fig. 11).

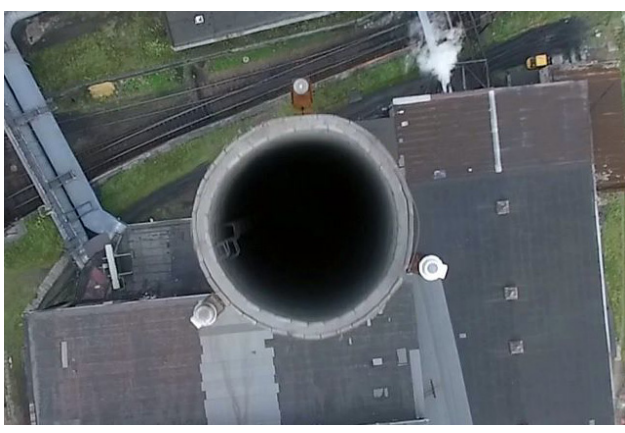

Fig. 10. Ovalisation of the chimney shaft crosssection at the flue gas outlet level

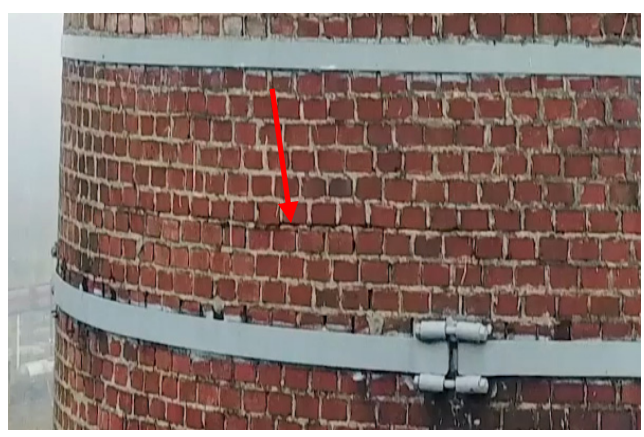

Fig. 11. Crack at the chimney wall - a photo taken by a drone in November 2017

\section{Summary}

For decades, observations of buildings and structures in regions impacted by underground mining have been made using two methods, these being geodetic measurements of structural deformations and foundations and visual inspections of the technical condition. In many situations such procedures have proven insufficient. Frequently, their use is prevented by inaccessibility of the object or its part.

The experience and knowledge gained from monitoring the chimney indicates that it is reasonable to use laser sensors which facilitate the continuous measurement of deflection in real time. The measurement results can easily be transmitted, and exceedance of threshold values can be signalled.

With 3D laser scanners, changes in the geometry of buildings and structures can be monitored. Terrestrial scanning is a source of information about the condition of buildings and their damage, caused by mining. The colour 3D image created from millions of pieces of measurement data can be used for further operations and analyses, including measurements and 3D modelling. The data obtained from laser scanning adds a new quality to mining damage inventory and monitoring processes.

\section{References}

1. A. Szade : Polish patent no 151105

2. P. Gruchlik: Naziemne skanowanie laserowe 3D, doświadczenia i perspektywy. Przegląd Górniczy 5. (2015)

3. W. Mika, A. Ferenc, S. Czaja: Monitoring obiektów budowlanych z zastosowaniem drona. Przegląd Górniczy 1(2018) 